\title{
INCUBAÇÃO DO VERDETE COM DIFERENTES FONTES DE ÁCIDOS PARA DISPONIBILIZAÇÃO DE POTÁSSIO, CÁLCIO, MAGNÉSIO DO SOLO
}

\author{
A. A. SILVA* e R. M. Q. LANA \\ Instituto de Ciências Agrárias - Universidade Federal de Uberlândia \\ adriane@iciag.ufu.br
}

Artigo submetido em julho/2015 e aceito em setembro/2015

DOI: $10.15628 /$ holos.2015.3210

\section{RESUMO}

A rocha verdete é uma fonte possível de utilização como fertilizante potássico, com concentração de $13 \%$ de $\mathrm{K}_{2} \mathrm{O}$ total, rocha pelítica rica em ilita com glauconita (filossilicato hidratado de potássio e ferro, do grupo da mica). Porém há uma limitação para melhorar sua disponibilização, sendo assim objetivou-se caracterizar o verdete quanto ao potencial de utilização agrícola, observar se ocorrerá aumento da disponibilidade de potássio, cálcio, magnésio quando o verdete for submetido a diferentes doses de ácido húmico e ácido fosfórico. Os testes de incubação foram realizados em potes de poliuretano com uso de LATOSSOLO VERMELHO de textura argilosa, o qual foram incubados tratamentos de diferentes doses de acido fosfórico; acido fosfórico+ acido húmico; acido humico. O ensaio foi conduzido por 90 dias, foram realizadas 2 coletas, aos 45 dias e 90 dias após a incubação. Realizou-se a determinação dos teores de potássio Houve efeito na disponibilização de potássio nos diferentes tratamentos e dosagens dos ácidos. A liberação de potássio foi maior quando se utilizou o ácido húmico de forma exclusiva. Porém houve efeito da utilização do acido fosfórico e do acido fosfórico + ácido húmico, sendo o incremento variando de 235 a $1.000 \%$. O cálcio, em relação ao tratamento controle observou-se um incremento de 53 a 75\%. E o magnésio apresentou comportamento similar ao cálcio. Sendo assim concluiu-se que o verdete apresentou-se uma fonte de potássio com aumento da solubilização quando submetido a ataque dos ácidos testados. O ácido húmico foi a fonte de ácido que melhor disponibilizou o K. Há efeito das doses de ácido na disponibilização do K, Ca e Mg pela Rocha verdete.

PALAVRAS-CHAVE: Rochagem Potássica; ácido húmico; ácido fosfórico; disponibilização de nutrientes.

\section{INCUBATION OF VERDETE WITH ACID TO DIFFERENT SOURCES AVAILABLE POTASSIUM, CALCIUM, SOIL MAGNESIUM}

\begin{abstract}
The verdete rock is a possible source for use as a potassium fertilizer, with a concentration of $13 \%$ total $\mathrm{K}_{2} \mathrm{O}$, rich pelitic rock illite with glauconite (phyllosilicate hydrated potassium and iron, mica group). But there is a limitation to improve its availability, so the objective was to characterize the verdigris of the potential of agricultural use, see if occur increased availability of potassium, calcium, magnesium when the verdete is subjected to different doses of humic acid and phosphoric acid. Incubation tests were conducted in jars with polyurethane use Dystrophic Red clayey, which were incubated treatments of different doses of phosphoric acid; phosphoric acid + humic acid; humic acid, and increasing the range the 235 to $1.000 \%$. The test was conducted for 90 days, two samples were taken
\end{abstract}

at 45 days and 90 days after hatching. Carried out to determine the potassium content according to the methodology described by EMBRAPA (2009). Was no effect on the availability of potassium in the different treatments and dosages of acids. Potassium release was higher when using humic acid exclusively. However, there was effect of the use of phosphoric acid and phosphoric acid + Humic acid. Calcium compared to the control we observed an increase 53-75\%. And magnesium showed behavior similar to calcium. Thus it was concluded that verdigris presented to a source of potassium, increased solubility when subjected to attack by the acids tested. The humic acid was the source of acid that provided the best $\mathrm{K}$. There effects of acid doses in providing $\mathrm{K}, \mathrm{Ca}$ and $\mathrm{Mg}$ by verdete Rock.

KEYWORDS: Stonemeal Potassic; humic acid; phosphoric acid; availability of nutrients. 


\section{INTRODUÇÃO}

Atualmente, a base de aplicação de potássio permanecem sendo o $\mathrm{KCl}$ e nessa fonte 0 Brasil apresenta grande dependência de fontes externas, pois não apresenta jazidas relevantes para serem exploradas. Estudos com formas representativas de potássio em solos estão sendo retomados (Medeiros et al. 2014).

Entre as principais fontes minerais, observa-se que há poucos reservas no Brasil, sendo as fontes alternativas uma possibilidade. Além do cloreto de potássio $(\mathrm{KCl})$, o sulfato de potássio (K2SO4), o sulfato duplo de potássio e magnésio (K2SO4.MgSO4-) e o nitrato de potássio (KNO3) também são utilizados. Juntos são as fontes mais importantes de $K$ na forma de fertilizantes minerais, sendo o K2SO4 o segundo mais utilizado (POTAFOS, 1996). Por conter de 58 a $62 \%$ de K2O solúvel em água, o cloreto de potássio é mais competitivo economicamente que os outros fertilizantes. Entretanto, devido ao alto teor de cloro, não pode ser utilizado em algumas culturas, como o abacaxi e o fumo, pois prejudica o valor comercial desses produtos. Apresentase ainda, como restrição ao uso desse fertilizante, o fato de não ser aceito na agricultura orgânica devido à elevada solubilidade e presença de cloro (COSTA \& CAMPANHOLA, 1997; MALAVOLTA et al., 2002).

Após o nitrogênio, o potássio é o macronutriente requerido em maior quantidade pelas culturas, entretanto, diferentemente do nitrogênio, que pode ser disponibilizado por processos de fixação biológica, não existem fontes renováveis de potássio, de modo que, sua disponibilidade às plantas depende essencialmente das reservas do solo e da aplicação de fertilizantes. Nas condições brasileiras, o problema agrava-se ainda mais, pelo fato dos solos serem pobres em minerais contendo potássio e apresentarem baixa capacidade de retenção de cátions, o que favorece a lixiviação desse nutriente para fora da zona de crescimento radicular (VILELA et al., 2004; CURI et al., 2005). De acordo com CALMAK (2005), o K é o cátion mais abundante no tecido das plantas, possuindo diversas funções fisiológicas, dentre elas: elongação celular, resistência estomática e influência na taxa fotossintética. O mesmo autor cita que há evidências de que a produção de espécies reativas de oxigênio nos cloroplastos é intensificada sob baixo suprimento de potássio, ocasionando clorose e necrose nas folhas. A dependência de importações desse fertilizante, além de desfavorecer a balança comercial brasileira, implica em questões estratégicas como a necessidade de negociações com um grupo restrito de países fornecedores para a compra de um insumo essencial à produção agrícola (RESENDE et al., 2006).

De acordo com Lopes (2005) o Brasil detém 3,5\% das reservas potássicas do mundo. Porém as reservas conhecidas são poucas e a importação dessa fonte fazem com que o agronegócio brasileiro seja dependente das industrias fertilizantes estrangeiras. Sendo assim objetivou-se avaliar a disponibilidade de $\mathrm{K}, \mathrm{Ca}$ e $\mathrm{Mg}$ com a utilização de diferentes ácidos no verdete.

\section{REVISÃO BIBLIOGRÁFICA}

O Verdete possui na sua composição principalmente glauconita, feldspatos, micas e outros minerais (quartzo) e é encontrada predominantemente na região do AltoParanaíba (Estado de Minas Gerais), nas imediações dos municípios de Abaeté, Carmo do Paranaíba, Cedro do Abaeté, Dores do Indaiá, Estrela do Indaiá, Matutina, Papagaios, Rio Paranaíba, São Gotardo, 
Serra da Saudade e Tiros. As áreas distam aproximadamente 270 quilômetros de Belo Horizonte, percorrendo-se $185 \mathrm{~km}$ pela BR262 e $85 \mathrm{~km}$ pela da rodovia MG-235 até a cidade de São Gotardo. $\mathrm{O}$ acesso às outras localidades na área de influencia do jazimento é feito pelas rodovias BR-354, MG-000 e por estradas não pavimentadas. Geologicamente, encontra-se no Cráton do São Francisco, no Grupo Bambuí, na Formação Serra da Saudade. A formação é constituída por folhelhos intercalados com Verdetes, em alternância centimétrica a métrica, com alguns níveis de fosforita no topo (PIZA et al., 2009).

Segundo OLIVEIRA \& SOUZA (2001), oficialmente as reservas de sais de potássio no Brasil são de cerca de 14,5 bilhões de toneladas na forma do minério silvinita, mistura de silvita ( $\mathrm{KCl}$ ) com halita $(\mathrm{NaCl})$, e do mineral carnalita $(\mathrm{KCl} \cdot \mathrm{MgCl} 2.6 \mathrm{H} 2 \mathrm{O})$, estando estas situadas nos Estados de Sergipe, Amazonas (Bacias Sedimentares Sergipe/Alagoas e do Amazonas) e Tocantins. Entretanto, apenas uma mina produz fertilizantes potássicos no país, a de Taquari-Vassouras, situada no município de Rosário do Catete, em Sergipe (LOPES, 2005), a qual, a atual detentora dos direitos de lavra é a Companhia VALE (NASCIMENTO \& LOUREIRO, 2004).

Apesar da pequena extensão das reservas brasileiras com $\mathrm{KCl}$, existem inúmeras rochas silicatadas que contêm potássio, sendo estas ricas em flogopita ou biotita, ou seja, minérios abundantes no Brasil, com potencial de uso como fertilizante em sua forma moída (BARBOSA FILHO et al., 2006).

De acordo com APARECIDA DA SILVA (2009), as rochas ou minerais industriais com elevados teores de potássio podem ser utilizados como fontes alternativas para a produção de sais de potássio ou aplicados diretamente no solo, como fertilizantes de liberação lenta. Deste modo, o desenvolvimento de um novo insumo agrícola, derivado de uma rocha, existente no território nacional, beneficiaria tanto o setor agrícola quanto mineral.

Segundo MARTINS et al. (2008), estudos em casa de vegetação usando rochas moídas (brecha vulcânica alcalina, biotita-flogopita xisto e ultramáfica alcalina) como fontes de $\mathrm{K}$ para soja e milheto, mostraram resultados promissores.

Dentre estas rochas, o verdete de Cedro do Abaeté, município que está situado na Bacia do Rio São Francisco, no Estado de Minas Gerais (Brasil), a 285 km de Belo Horizonte, se destaca pelo teor de K2O (6 a 14\%) e pela existência de íons Fe2+ (TOLEDO PIZA et al., 2011; SILVA, et al., 2012).

O verdete é uma rocha pelítica rica em ilita com glauconita (filossilicato hidratado de potássio e ferro, do grupo da mica), apresenta coloração verde (devido à glauconita) e possui teores variáveis de $\mathrm{K} 2 \mathrm{O}$ e fosfato (LIMA et al., 2007). Ocorre intercalado nas rochas da Formação Serra da Saudade em forma de lentes de espessuras variáveis, desde centimétricas até métricas. Esta ocorrência é importante, pois como está associada à Formação Serra da Saudade serviu como um dos critérios para associação das rochas onde afloram o siltito com intercalações de verdete e fosforito com esta unidade estratigráfica (OLIVEIRA, 2011).

\section{METODOLOGIA}

O experimento foi conduzido no Laboratório de Análise de Solos, Fertilizantes, Foliar e Resíduos Orgânicos da Universidade Federal de Uberlândia. Determinou-se a caracterização do verdete, quanto às características químicas, as quais estão descritas na Tabela 1. Foram 
realizadas quatro metodologias para avaliar a disponibilidade de nutrientes das fontes de fertilizantes: Potássio solúvel em $\mathrm{H} 2 \mathrm{O}$, método com uso de $\mathrm{HCl}$ (1:1), determinação de $\mathrm{K}$ total e determinação em H2SO4, segundo EMBRAPA (2009). A metodologia mais utilizada para verificar a disponibilização de $\mathrm{K}$ para sub-produtos de rochagem é a de $\mathrm{K} 2 \mathrm{O}$ total. A metodologia é descrita pela utilização de uma solução com os seguintes ácidos $(10 \mathrm{~mL}$ de ácido clorídrico, $10 \mathrm{~mL}$ de ácido nítrico, $10 \mathrm{~mL}$ de ácido fluorídrico e $5 \mathrm{~mL}$ de ácido perclorico). Adicionou-se $0,5 \mathrm{~g}$ da rocha e levou-se a chapa aquecedora até a secura total. Após o tempo para secagem na chapa aquecedora adicionou-se $30 \mathrm{~mL}$ de ácido clorídrico e retornou o Becker novamente para a chapa aquecedora por alguns minutos. Colocou-se a amostra em um balão de $500 \mathrm{~mL}$ e completou o restante com água destilada. Após filtragem do material, pipetou-se $5 \mathrm{~mL}$ da solução filtrada e adicionou- se em um balão de $250 \mathrm{~mL}$ completando o volume com água destilada e em seguida fez-se a leitura.

Com o uso da metodologia de extração em H2O (Tabela 1), observou-se que os teores variaram de 0 a $0,4 \%$. Isso indica que a solubilidade das fontes em condições naturais tem baixo aproveitamento. Já com uso de $\mathrm{HCl}$ (1:1), observou-se que o termopotássio apresentou disponibilidade de $1,96 \%$ e as demais fontes ficaram próximas de 0,80\%. Já com aplicação do $\mathrm{H} 2 \mathrm{SO} 4$ na rocha o comportamento foi similar ao da utilização de $\mathrm{HCl}$ (1:1), porém o verdete apresentou menor disponibilidade, com valor próximo de 0,32\%.

Tabela 1- Disponibilidade de K2O pela fonte verdete com 4 diferentes metodologias de determinação.

\begin{tabular}{|c|c|c|c|c|}
\hline Tratamento & Solúvel em $\mathrm{H}_{2} \mathrm{O}$ & $\mathrm{K}_{2} \mathrm{O}$ Total & $\mathrm{HCl} 1: 1$ & $\mathrm{H}_{2} \mathrm{SO}_{4}$ \\
\hline & \multicolumn{4}{|c|}{ 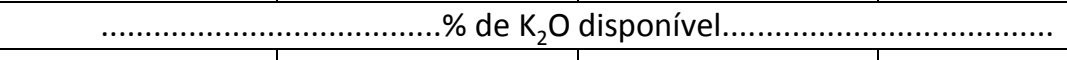 } \\
\hline Verdete & 0,4 & 13 & 0,88 & 0,32 \\
\hline
\end{tabular}

O experimento foi instalado em delineamento inteiramente casualizado, cujos tratamentos estão descritos a seguir:

T1 - verdete submetido a presença de ácido fosfórico na dose de 0,25 L por $100 \mathrm{~kg}$ verdete. $\mathrm{T} 2$ - verdete submetido a presença de ácido fosfórico na dose de 0,50 L por $100 \mathrm{~kg}$ verdete. T3 - verdete submetido a presença de ácido fosfórico na dose de 0,75 L por $100 \mathrm{~kg}$ verdete. T4 - verdete submetido a presença de ácido fosfórico na dose de 1,00 L por $100 \mathrm{~kg}$ verdete. T5 - verdete submetido a presença de ácido húmico na dose de $3 \mathrm{~L}$ por $100 \mathrm{~kg}$ verdete.

T6 - verdete submetido a presença de ácido húmico na dose de $6 \mathrm{~L}$ por $100 \mathrm{~kg}$ verdete.

T7 - verdete submetido a presença de ácido húmico na dose de $9 \mathrm{~L}$ por $100 \mathrm{~kg}$ verdete.

T8 - verdete submetido a presença de ácido húmico na dose de $12 \mathrm{~L}$ por $100 \mathrm{~kg}$ verdete.

T9 - verdete submetido a presença de ácido fosfórico na dose de 0,50 L por $100 \mathrm{~kg}$ verdete + submetido a presença de ácido húmico na dose de $3 \mathrm{~L}$ por $100 \mathrm{~kg}$ verdete.

T10 - verdete submetido a presença de ácido fosfórico na dose de 0,50 L por $100 \mathrm{~kg}$ verdete + submetido a presença de ácido húmico na dose de $6 \mathrm{~L}$ por $100 \mathrm{~kg}$ verdete.

T11 - verdete submetido a presença de ácido fosfórico na dose de 0,50 L por $100 \mathrm{~kg}$ verdete + submetido a presença de ácido húmico na dose de $9 \mathrm{~L}$ por $100 \mathrm{~kg}$ verdete.

T12 - verdete submetido a presença de ácido fosfórico na dose de 0,50 L por $100 \mathrm{~kg}$ verdete + submetido a presença de ácido húmico na dose de 12 L por 100 kg verdete.

T13 - testemunha com aplicação do verdete mas sem a presença dos ácidos. 
Os testes de incubação foram realizados em potes de poliuretano com capacidade de 1000 gramas, com uso de LATOSSOLO VERMELHO de textura argilosa, o qual foram incubados com cada um dos tratamentos citados acima.

Os ensaios foram conduzidos 90 dias, sendo os tratamentos mantidos em $70 \%$ da capacidade de campo. Foram realizadas 2 coletas, aos 45 dias e 90 dias após a incubação. Ao término do período de incubação, as amostras foram encaminhadas ao Laboratório de Solos da Universidade Federal de Uberlândia para quantificação das variáveis analisadas no solo aos resíduos aplicados. Realizou-se as seguintes determinações: $\mathrm{pH}$ em água e macronutrientes (K, $\mathrm{Ca}, \mathrm{Mg}$ ), segundo metodologia descrita pela EMBRAPA (2009).

\section{RESULTADOS E DISCUSSÃO}

Em relação aos valores de pH em água (Figura 1), observa-se que o ácido fosfórico reduziu linearmente os valores de $\mathrm{pH}$.

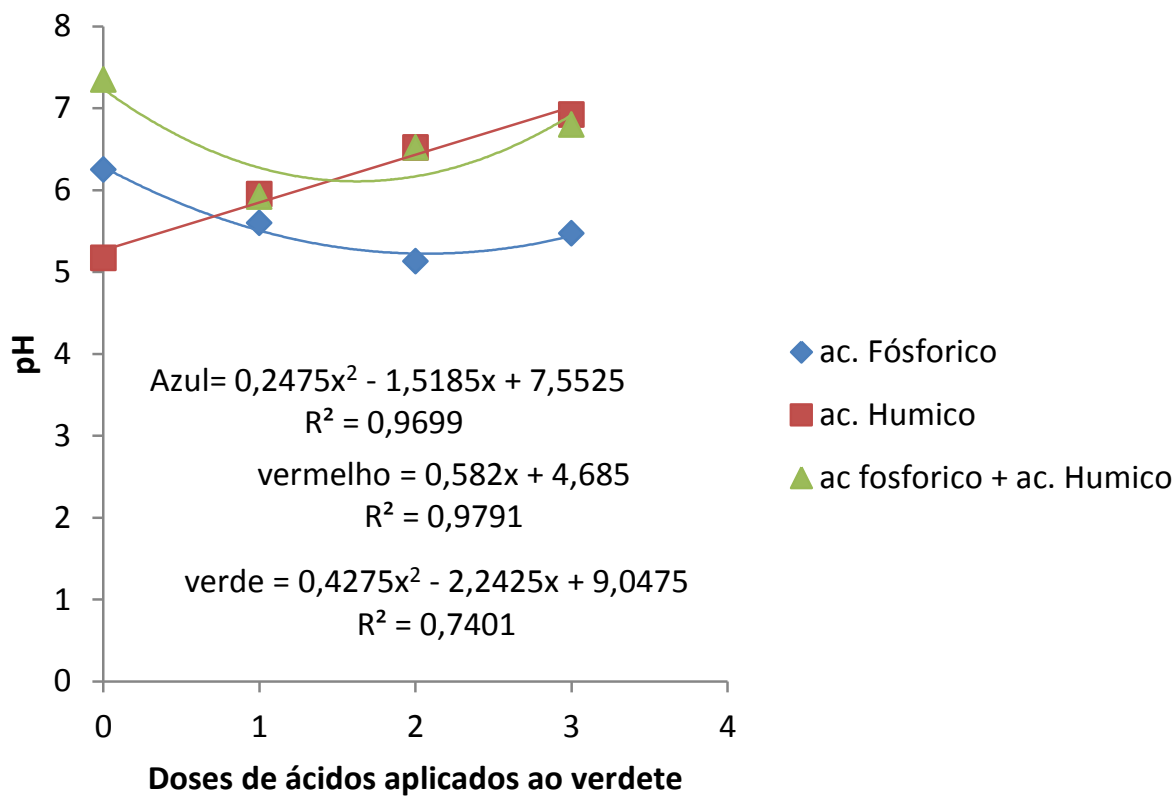

Figura 1 - Valores de pH de amostras de solo submetidos a aplicação verdete com diferentes doses de ácido (fosfórico, acido húmico e fosfórico + húmico) após $\mathbf{4 5}$ dias de incubação.

A extração com ácido húmico + acido fosfórico apesar do declínio em relação a dose controle (sem aplicação de ácido), acarretou uma tendência de aumento do pH (Figura 1). Já a aplicação exclusiva de ácido húmico foi o tratamento que promoveu as maiores valores de $\mathrm{pH}$, com aumento linear até a maior dose. Isto se deve provavelmente ao ácido húmico, ser fonte de matéria orgânica estabilizada e os ácidos carboxílicos e fenólicos da matéria orgânica, contem grandes quantidades de carga negativa que podem ter retirado ions hidrogênios da solução acarretando aumento de $\mathrm{pH}$. Os valores de $\mathrm{pH}$ de amostras de solo submetidos a aplicação de verdete com diferentes doses de ácido (fosfórico, acido húmico e fosfórico + húmico) após 45 dias de incubação apresentaram-se dentro de valores adequados para os cultivos, que estão de acordo com a CFSEMG (1999) entre 5,5 a 7. 
Após mais 45 dias de incubação aos 90 dias, observa-se que houve uma alteração no valor de $\mathrm{pH}$, em relação a primeira avaliação, em todas as doses avaliadas (Figura 2).

Com relação aos tratamentos do verdete submetidos a presença do ácido fosfórico, observa-se que o mesmo foi o tratamento com menores valores de $\mathrm{pH}$. Aos 45 dias (Figura 1) observa-se que o solo inicialmente alcalino $(7,25)$, apresentou variação na presença do verdete com presença de ácido fosfórico, de 6,25 a 5,13, aos 45 dias.

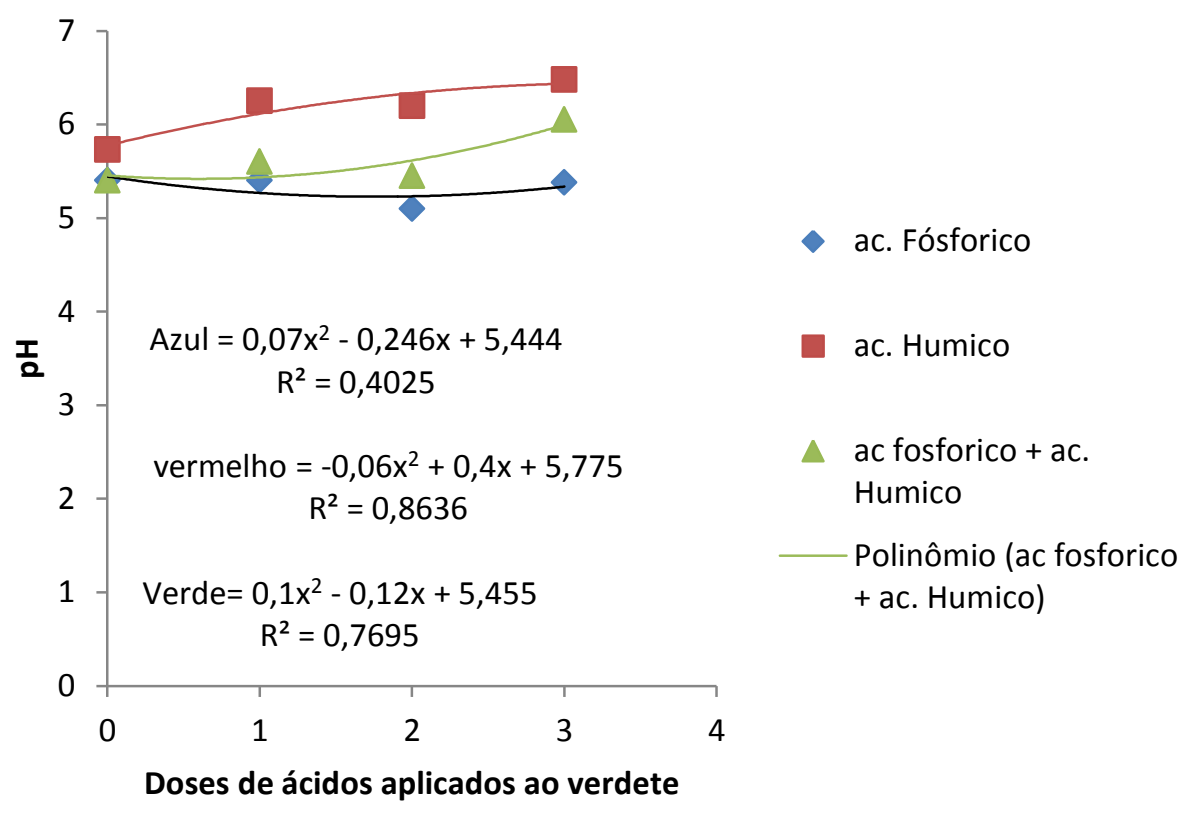

Figura 2 - Valores de pH de amostras de solo submetidos a aplicação de verdete com diferentes doses de ácido (fosfórico, acido húmico e fosfórico + húmico) após 90 dias de incubação.

$\mathrm{O}$ ácido fosfórico exclusivo reduziu o valor $\mathrm{pH}$ pois o produto de sua reação libera acidez para o solo. Aos 90 dias o perfil do $\mathrm{pH}$ foi alterado, inclusive no tratamento controle $(5,40)$, e nos demais tratamentos com ac. Fosfórico os valores de $\mathrm{pH}$ foi de 5,38 a 5,00. O que indica que após o período de incubação de 90 dias, há uma influencia dos tratamentos sobre o verdete.

O solo utilizado é argiloso com elevado poder tampão e com 90 dias pode-se observar a resposta dos extratores em relação a estabilização de resposta do solo com a rocha (Figura 2).

Já com os demais tratamentos em que houve a inclusão do ácido húmico de forma exclusiva e conjunta com acido fosfórico, observou-se um incremento no valor de $\mathrm{pH}$. Nos tratamentos com verdete associado ao ac. Fosfórico e ac. Húmico, aos 45 dias observou-se que houve uma variação entre 7,35 a 5,92 (Figura 1). Esses teores são superiores aos observados com o uso exclusivo do ac. Fosfórico. Aos 90 dias a variação de $\mathrm{pH}$ foi de 5,45 a 6,12 (Figura 2), em que observou-se uma tendência de incremento em função da dose dos ácidos aplicados sendo que os teores observados estão todos dentro dos padrões considerados ideais para o cultivo das espécies agrícolas $(5,5$ e 6,0) de acordo com a CFSEMG (1999).

Com o uso exclusivo de ácido húmico aos 45 dias, observou-se que houve um aumento de valores de $\mathrm{pH}$ em relação ao aumento das doses do ácido com variações 
entre 5,17 e 6,92. Já aos 90 dias, observou-se que o efeito do tempo de incubação foi fundamental para a manutenção dos valores de $\mathrm{pH}$ alcançados em que a variação foi de 5,73 a 6,48 , sendo comprovada o efeito benéfico do ac. húmico, como condicionador de solo. Esse tratamento foi o que nas duas datas de avaliação promoveu os maiores valores de $\mathrm{pH}$. Esse comportamento como condicionante de solos do ácidos húmicos (AH) são descritos por RAUSA et al., 1994.

A aplicação dos ácidos promoveram incrementos na disponibilização de $\mathrm{K}$ em todos os tratamentos (Figura 3). A aplicação de ácido fosfórico de forma exclusiva para aumentar a disponibilidade do verdete, foi o tratamento da rocha moída que menos promoveu a disponibilização de K. Nesse tratamento, independente da dose de ácido fosfórico utilizado, o

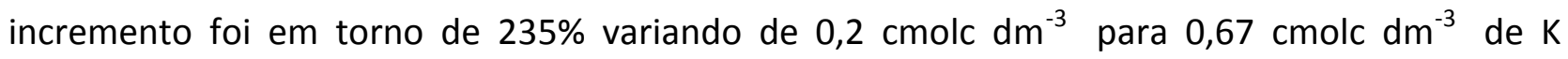
disponível.
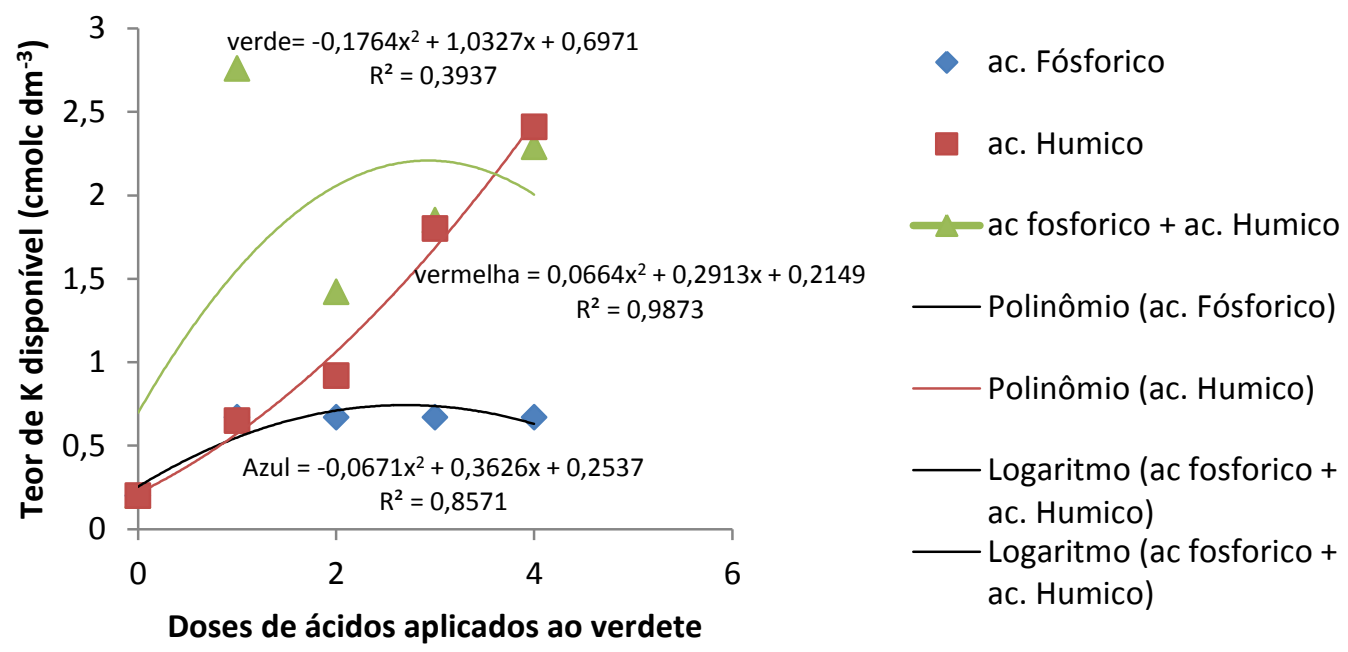

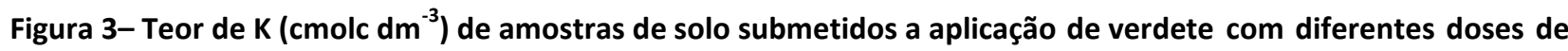
ácido (fosfórico, acido húmico e fosfórico + húmico) aos 45 dias.

$\mathrm{Na}$ disponibilização de K (Figura 3) o que apresentou um comportamento mais regular com coeficiente de determinação de 0,98 , foi o ácido húmico. A disponibilidade de $\mathrm{K}$ foi linear em função das doses de ácido húmicos aplicados (Figura 3). 0 incremento observado foi de 0,65 a

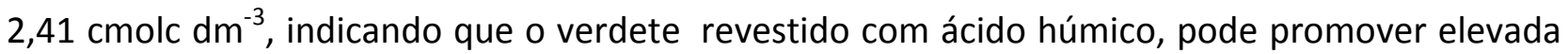
disponibilização de $\mathrm{K}$, chegando a incrementos superior a $1.000 \%$. No tratamento com ac. Fosfórico + ac. Húmico, o comportamento não seguiu um padrão, com coeficiente de determinação muito baixo 0,39 . Houve incremento na disponibilidade do $K$, porém ele não foi crescente de acordo com o incremento da dose de ácidos aplicados.

Neste experimento utilizou-se uma dose única de verdete e doses diferenciadas e crescentes dos ácidos, visando avaliar o efeito na solubilização da rocha. Recomenda-se realizar um experimento com aumento das doses de verdete para verificar qual a dose é melhor para disponibilizar $\mathrm{K}$ de forma equivalente ao $\mathrm{KCl}\left(58 \%\right.$ de $\left.\mathrm{K}_{2} \mathrm{O}\right)$, fonte considerada padrão na aplicação de potássio.

Já aos 90 dias observa-se que a disponibilização do Ca pelo uso do ac. Fosfórico foi nula, já quando associado com ácido húmico ou com ácido húmico de forma exclusiva houve 
incremento em relação ao tratamento controle (dose zero). Esse comportamento indica que houve grande efeito do ac. húmico na melhor disponibilização de $\mathrm{Ca}$. Na maior dose, o incremento foi de até $100 \%$.

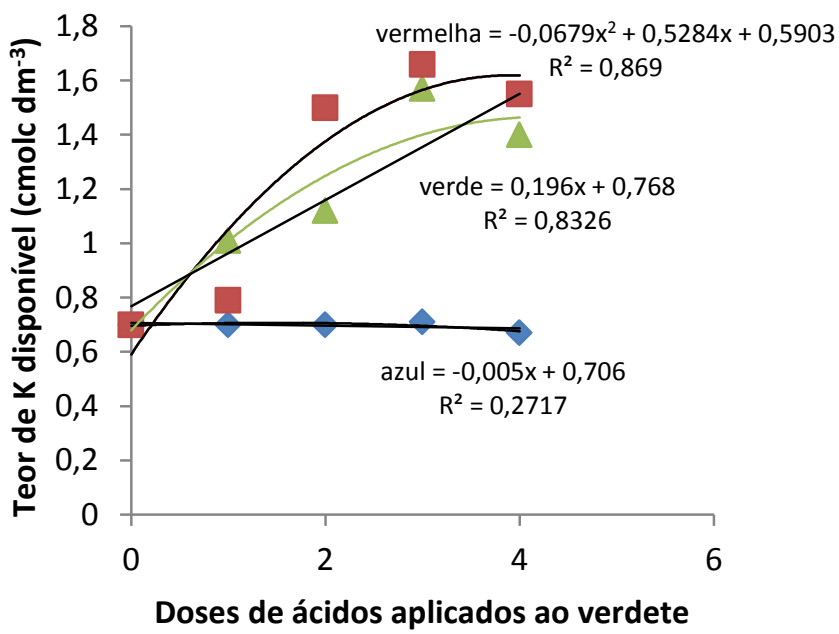

ac. Fósforico

ac. Humico

- ac fosforico + ac. Humico

- Logaritmo (ac fosforico + ac. Humico)

_ Polinômio (ac fosforico + ac. Humico)

Figura 4- Teor de $\mathrm{K}$ ( $\mathrm{cmolc} \mathrm{dm}^{-3}$ ) de amostras de solo submetidos a aplicação de verdete com diferentes doses de ácido (fosfórico, acido húmico e fosfórico + húmico) aos 90 dias.

Em relação ao teor de Ca disponível (Figura 5), observa-se que a maior disponibilização ocorreu com o uso do ácido fosfórico exclusivo, com teores variando entre 1,50 a 1,73. Em relação ao tratamento controle observou-se um incremento de 53 a 75\%. Nos tratamentos com aplicação de ácido húmico de forma exclusiva ou com ácido fosfórico, observou-se o comportamento similar, com variação entre 1,02 a 1,5, o que representa incrementos de até $50 \%$.

Aos 90 dias, pode-se perceber que houve pouca diferença entre as doses dos produtos na disponibilização do Ca (Figura 6). Ambos os tratamentos mantiveram-se com os teores equivalentes. $\mathrm{O}$ que comprova que as maiores liberações foram observadas aos 45 dias e após, os teores mantiveram-se estabilizados.

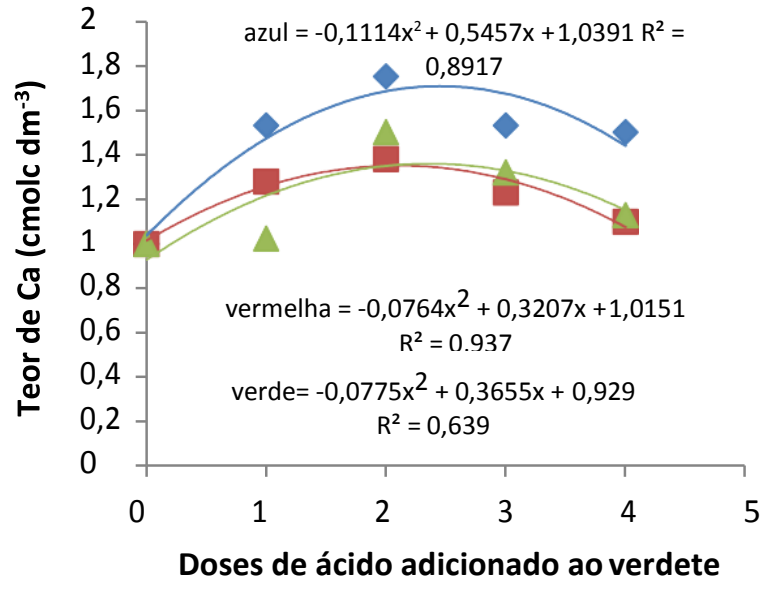

$\checkmark$ ac. Fósforico $\square$ ac. Humico $\triangle$ ac fosforico + ac. Humico

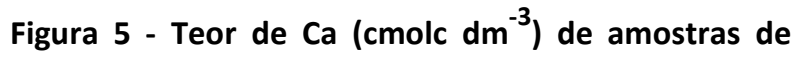
solo submetidos a aplicação de verdete com diferentes doses de ácido (fosfórico, acido húmico e fosfórico + húmico) aos 45 dias.

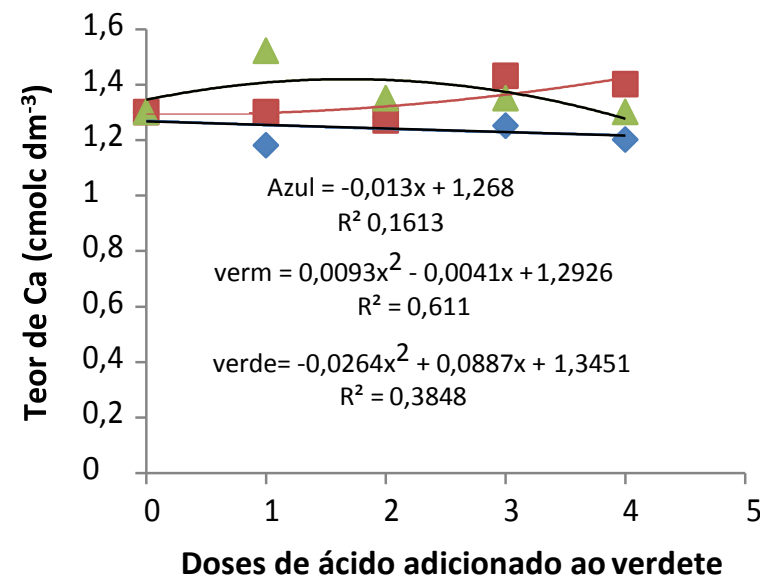

$\checkmark$ ac. Fósforico $\square$ ac. Humico $\triangle$ ac fosforico + ac. Humico Figura 6 - Teor de Ca (cmolc $\mathrm{dm}^{-3}$ ) de amostras de solo submetidos a aplicação de verdete com diferentes doses de ácido (fosfórico, acido húmico e fosfórico + húmico) aos 90 dias. 
Em relação ao Mg (Figura 7) observou-se o mesmo comportamento do cálcio. Nos tratamentos aplicados ao verdete (Figura 7), independente do ácido utilizado para aumento da disponibilidade de nutrientes, houve incremento de magnésio entre 34 a 105\%.

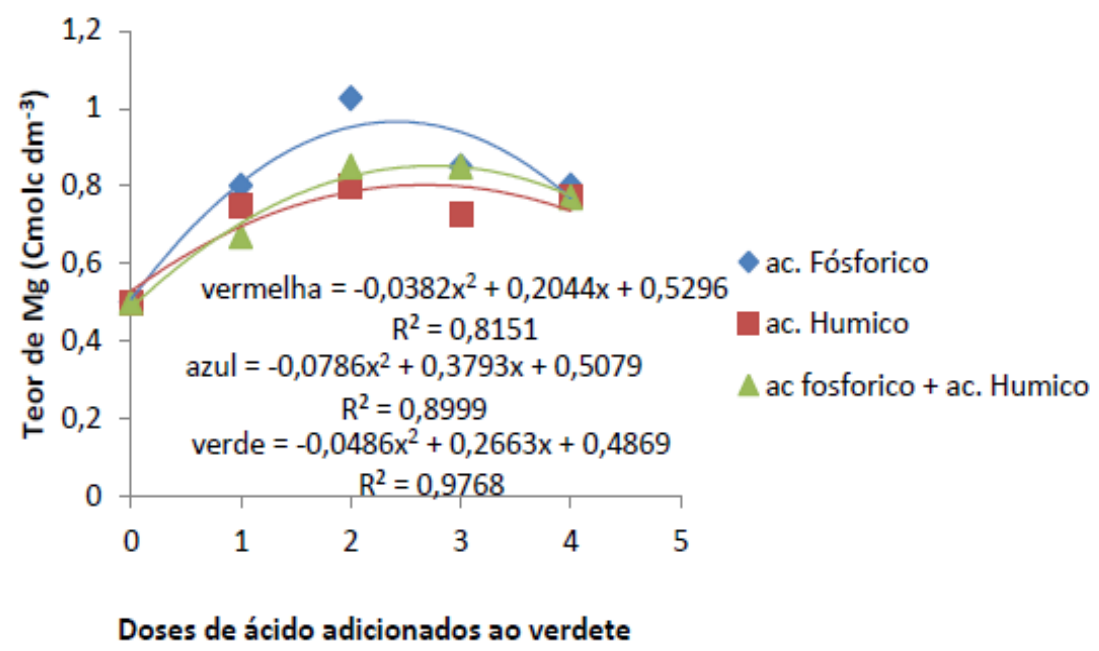

Figura 7 - Teor de $\mathrm{Mg}$ (cmolc dm-3) de amostras de solo submetidos a aplicação de verdete com diferentes doses de ácido (fosfórico, ácido húmico e fosfórico + húmico) aos $\mathbf{4 5}$ dias de incubação.

Aos 90 dias de incubação observou-se que os teores de Magnésio em um solo que originalmente apresentava teor próximo de 0,4 , teor abaixo do considerado ideal pela CFSEMG (1999), independente do tratamento o Mg apresentou teor próximo a 0,9 $\mathrm{cmolc} \mathrm{dm}^{-3}$, considerado ideal para algumas culturas.

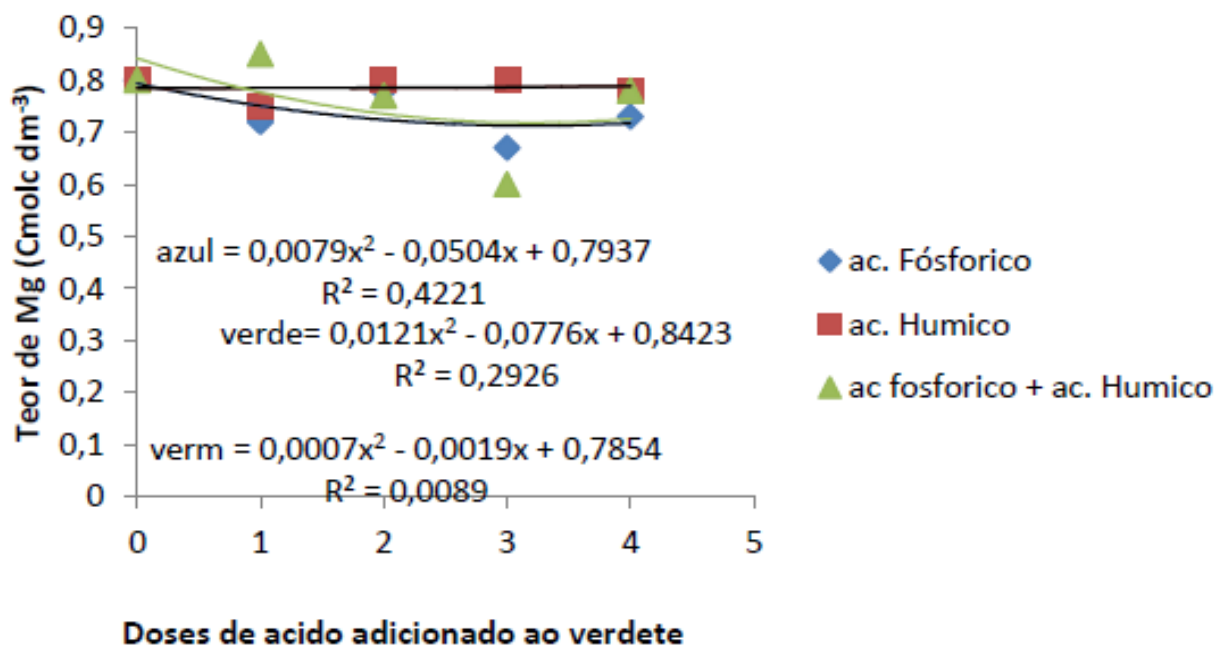

Figura 8 - Teor de $\mathrm{Mg}$ (cmolc dm-3) de amostras de solo submetidos a aplicação de verdete com diferentes doses de ácido (fosfórico, ácido húmico e fosfórico + húmico) aos 90 dias de incubação.

\section{CONCLUSÕES}

A rocha verdete foi eficiente para disponibilizar potássio para o solo, quando submetido aos diferentes tipos de ácidos (ácido fosfórico, ácido húmico e ácido. fosfórico + ácido húmico).

O ácido húmico resultou na maior solubilização do verdete na maioria das variáveis avaliadas. 
Os ácidos foram eficientes na solubilização do potássio e contribuíram para a aumento da disponibilidade de $\mathrm{Ca}$ e $\mathrm{Mg}$.

As técnicas utilizadas são possíveis de serem utilizadas visando um maior aproveitamento do verdete como fonte potássica, representando a valorização da rocha a qual a Vale é detentora de uma jazida.

A eficiência da utilização da rocha como fertilizante reduz os passivos ambientais.

\section{REFERÊNCIAS BIBLIOGRÁFICAS}

1. LOPES, A.S. Reservas de minerais potássicos e produção de fertilizantes potássicos no Brasil. In: YAMADA, T. \& ROBERTS, T.L., eds. Potássio na agricultura brasileira. Piracicaba, Associação Brasileira para a Pesquisa da Potassa e do Fosfato, 2005. p.21-32.

2. APARECIDA DA SILVA, E.; CASSIOLATO, A. M. R.; MALTONI, K. L.; SCABORA, M. H. Efeitos da rochagem e de resíduos orgânicos sobre aspectos químicos e microbiológicos de um subsolo exposto e sobre o crescimento de Astronium fraxinfolium Schott. Revista Árvore, Viçoça-MG, v. 32, n. 2, p.323-333, 2008.

3. BARBOSA FILO, M. P.; FAGERIA, N. K.; SANTOS, D. F.; COUTO, P. A. Aplicação de rochas silicáticas como fontes alternativas de potássio para a cultura do arroz de terras altas. Espaço \& Geografia, v. 9, n. 1, p. 63-84, 2006.

4. CALMAK, I. Protection of plants from detrimental effects of environmental stress factors. In: Potássio na agricultura brasileira. Anais do simpósio sobre Potássio na agricultura brasileira. Piracicaba: Associação Brasileira para pesquisa da potassa e do fosfato, 2005, p. 261-279.

5. COMISSÃO DE FERTILIDADE DO SOLO DO ESTADO DE MINAS GERAIS. Recomendações para o uso de corretivos e fertilizantes em Minas Gerais. 5. ed. Lavras, 1999. 359 p.

6. COSTA, M. B. B.; CAMPANHOLA, C. A agricultura alternativa no Estado de São Paulo. Jaguariúna: Embrapa-CNPMA, 1997, 63 p. (Documentos, 7).

7. CURI, N.; KÄMPF, N.; MARQUES, J. J. Mineralogia e formas de potássio em solos brasileiros. In: YAMADA, T.; ROBERTS, T. L. (Eds.). Potássio na agricultura brasileira. Piracicaba: Instituto da Potassa \& Fosfato, 2005. p. 91-122.

8. EMBRAPA - EMPRESA BRASILEIRA DE PESQUISA AGROPECUÁRIA. Manual de análises química de solos, plantas e fertilizantes. 2 ed. rev. e ampl.. Brasilia, DF; Embrapa informaçãos tecnologica, 2009, 627p.

9. LIMA, O. N. B.; UHLEIN, A.; BRITTO, W. Estratigrafia do Grupo Bambuí na Serra da Saudade e geologia do depósito fosfático de Cedro do Abaeté, Minas Gerais. Revista Brasileira de Geociência, v. 37, n. 4, p. 204-215, 2007.

10. MALAVOlTA, E.; PIMENTEl-GOMES, F.; ALCARDE, J. C. Adubos e adubações. São Paulo: Nobel, 2002. $200 \mathrm{p}$.

11. MARTINS, E. S., OLIVEIRA, C. G., RESENDE, A. V., MATOS, M. S. F. Agrominerais - rochas silicáticas como fontes minerais alternativas de potássio para agricultura. In: LUZ, A. B.; LINS, F. (Eds.). Rochas e minerais industriais - usos e especificações, 2008. p. 205-221.

12. MEDEIROS, J. S., Oliveira, F. H. T., Santos, H. C., Arruda, J. A., Vieira, M. S. Formas de potássio 
em solos representativos do Estado da Paraíba. Revista Ciência Agronômica, v. 45, n. 2, p. 417-426, abr-jun, 2014

13. NASCIMENTO, M.; LOUREIRO, F. E. L. Fertilizantes e sustentabilidade: o potássio na agricultura brasileira, fontes e rotas alternativas. Rio de Janeiro: CETEM/MCT, 2004, 66 p. (Série Estudos e Documentos, 61).

14. OliVeirA, L. A. M. de; SOUZA, A. E. Balanço Mineral Brasileiro 2001: potássio. 2001. Disponível em: http://www.dnpm.gov.br/assets/galeriadocumento/ balancomineral2001/potassio.pdf. Acesso em: 10 set. 2013.

15. OLIVEIRA, M. A. G. Mapeamento geológico (1:50.000) da região dos depósitos fosforíticos rocinha e lagamar, Oeste de Minas Gerais, com aplicação de aerogamaespectrometria e aeromagnetometria. Belo Horizonte, 2011. Trabalho de Graduação - Instituto de Geociências da Universidade Federal de Minas Gerais, 2011, 55 p.

16. ORIOLI JÚNIOR, V.; COUTINHO, E. L. M. Effectiveness of fused magnesium potassium phosphate for Marandú grass. Revista Brasileira de Ciência do Solo, Viçosa, v. 33, n. 6, p. 1855-1862, 2009.

17. POTAFOS. Nutri-fatos: informação agronômica sobre nutrientes para as culturas. Piracicaba: Potafos, 1996, 24 p. (Arquivo do Agrônomo, 10).

18. RAUSA, R.; GIRARDI, E.; CALÉMMA, V. Humic acids from coal: production, characterization and utilization. In: Senesi, N. \& Miano, T.M. (Eds.) Humic substances in the global environment and implications on human health. Elsevier, Oxford. p. 1225- 1244. 1994.

19. RESENDE, A. V. de; MARTINS, E. S.; OlIVEIRA, C. G. de; SENA, M. C. de; MACHADO, C. T. T.; KINPARA, D. I.; OLIVEIRA FILHO, E. C. de. Suprimento de potássio e pesquisa de uso de rochas "in natura" na agricultura brasileira. Espaço \& Geografia, v. 9, n. 1, p. 19-42, 2006.

20. Silva, A. A. S. da, Medeiros, M. E. , Sampaio, J. A. e Garrido, F. M. S. Caracterização do verdete de cedro do abaeté para o desenvolvimento de um material com liberação controlada de potássio. HOLOS, Ano 28, Vol 5, 2012.

21. TOLEDO PIZA, Patricia d'Almeida Toledo de et al. Verdete da região de cedro de abaeté (mg) como fonte alternativa para potássio. Geociência. (São Paulo) [online]. 2011, vol.30, n.3 [citado 2015-06-22], pp. 345-356 Disponível em: <http://ppegeo.igc.usp.br/scielo.php? script=sci_arttext\&pid=S0101-90822011000300003\&lng=pt\&nrm=iso>. ISSN 0101-9082.

22. VILELA, L.; SOUSA, D. M. G.; SILVA, J. E. Adubação potássica. In: SOUSA, D. M. G.; LOBATO, E. (Eds.). Cerrado: correção do solo e adubação. Planaltina: Embrapa Cerrados, 2004, p.169183. 